\title{
Expression of Chemically Synthesized $\alpha$-Neo-endorphin Genes under the Control of the PH05 Gene of Saccharomyces cerevisiae
}

\author{
Takehiro Oshima, Kenji Arima, Kumiko Matsubara, \\ Shoji Tanaka and Hiroshi NaKazato \\ Suntory Institute for Biomedical Research, \\ 1-1-1, Wakayamadai Shimamoto-cho, Mishima-gun, \\ Osaka 618, Japan
}

Received October 7, 1985

\begin{abstract}
A chemically synthesized $\alpha$-neo-endorphin ( $\alpha \mathrm{NE}$ ) gene was fused to the PHO5 gene which encodes repressible acid phosphatase (APase) of Saccharomyces cerevisiae. Three kinds of genes encoding APase- $\alpha$ NE chimeric proteins were cloned in the yeast. Nucleotide sequence analysis revealed that $\mathrm{C}$-terminal amino acids comprising 6 to $17 \%$ of the intact enzyme were replaced by $\alpha \mathrm{NE}$. The APase- $\alpha$ NE chimeric proteins were expressed at the level of approximately $1 \times 10^{6}$ molecules per cell under the derepressed conditions. The radioimmunoassay for $\alpha \mathrm{NE}$ revealed that most of the APase- $\alpha \mathrm{NE}$ chimeric proteins was not present in the periplasmic fraction but in the protoplast fraction.
\end{abstract}

The PH05 gene of the yeast, Saccharomyces cerevisiae, encodes a repressible acid phosphatase (APase). The expression of this gene is controlled by the concentration of inorganic phosphate $(\mathrm{Pi})$ through a complex genetic system including both negative and positive regulatory factors. ${ }^{1,2)}$ The repressible APase is secreted across the cytoplasmic membrane and localized in the periplasmic space. ${ }^{3)}$ The entire nucleotide sequence of the PHO5 gene was previously described. ${ }^{4)}$ From the sequence analysis results, the complete amino acid sequence of the APase was deduced and several unique sequences in the $5^{\prime}$ and $3^{\prime}$ non-coding regions of the PHO5 gene were found. Furthermore, comparison of the $\mathrm{N}$-terminal amino acid sequence thus deduced with that of the purified repressible APase revealed the existence of a putative signal peptide in the precursor protein. ${ }^{4)}$

Since the expression of the PHO5 gene can be controlled by the Pi concentration and its gene product is localized in the periplasmic space of the yeast cells, the PHO5 gene seems to be a novel potent tool for the expression of exogeneous genes in the yeast. To investigate this possibility, we employed a chemically synthesized $\alpha$-neo-endorphin $(\alpha \mathrm{NE})$ gene, which we reported previously, ${ }^{5)}$ as a foreign gene. Alpha NE is an endogenous opiate peptide comprising ten amino acid residues with the sequence of H-Tyr-Gly-Gly-Phe-Leu-ArgLys-Tyr-Pro-Lys-OH. ${ }^{6}$ ) We have constructed chimeric genes, $P H 05-\alpha \mathrm{NE}$, by fusing the $\alpha \mathrm{NE}$ gene to the truncated $3^{\prime}$ portion of the PHO5 structural gene, which had been generated through nuclease Bal 31 digestion. It was expected that the chimeric genes would be expressed under the control of the PHO5 promoter and the gene products would contain the signal peptide of the APase. The direct expression of a foreign gene using the PHO5 promoter region has already been described. ${ }^{7)}$

Radioimmunoassay after cultivation of yeast cells transformed by the plasmid containing the fused genes revealed that approximately $10^{6}$ molecules of $\alpha \mathrm{NE}$ per cell were produced under the conditions of a low concentration of inorganic phosphate in the medium. The localization of the acid phosphatase- 
$\alpha \mathrm{NE}$ chimeric proteins in the yeast cells was also investigated.

\section{MATERIALS AND METHODS}

Strains and media. As hosts, E. coli strain JA221 (recA1 leuB6 $\operatorname{trp} \mathrm{E} 5 \mathrm{hsd} \mathrm{R}^{-} h s d \mathrm{M}^{+}$lac $\left.\mathrm{Y}\right)$ and Saccharomyces cerevisiae XP3-7A (MATa leu2 his4 trp1 pho5) were used. ${ }^{4)}$ Media for the growth of the host strains were the same as described previously. ${ }^{4)}$

Enzymes and reagents. Restriction endonucleases and other enzymes except Bal 31 were obtained as previously described. ${ }^{4)}$ Nuclease Bal 31 was purchased from New England Biolabs Inc. Zymolyase-60,000 was from Seikagaku Kogyo Co., Ltd., Japan.

Chemical synthesis of the $\alpha$-neo-endorphin $(\alpha N E)$ gene. Double-stranded DNA (dsDNA) containing the $\alpha$ NE gene was constructed from synthetic oligodeoxyribonucleotides. The nucleotide sequence is shown in Fig. 1. Synthesis of oligodeoxyribonucleotides and construction of dsDNA were performed essentially as described previously. ${ }^{5}$ The dsDNA was inserted between the EcoRI and BamHI sites of a plasmid derived from $\mathrm{pBR} 322$, and the resulting plasmid was designated as $\mathrm{p} \alpha \mathrm{NE} 5$.

Construction of plasmids. For the construction of an expression vector carrying a $P H 05-\alpha \mathrm{NE}$ chimeric gene, p $\alpha$ NE5 described above, pYE207 carrying the selection marker gene LEU2 and one of the inverted repeat sequences of $2 \mu \mathrm{m}$ DNA, IR $1,{ }^{3)}$ which contains the replication origin, and pYE1170 $\Delta$ carrying partially deleted PHO5 genes were used.

The construction of pYE1170 $\Delta$ was as follows (Fig. 2). Five $\mu \mathrm{g}$ of $\mathrm{pYE} 1101^{4)}$ was digested with $\mathrm{HpaI}$ and the larger fragment was isolated and ligated with $1 \mu \mathrm{g}$ of phosphorylated EcoRI linker with T4 DNA ligase. After transformation of $E$. coli JA221, pYE1170 carrying EcoRI linker, which had been inserted into the $\mathrm{HpaI}$ site of the 7.9-kilobase $(\mathrm{kb})$ fragment of pYE1101, was obtained from among the ampicillin-resistant transformants. Five $\mu \mathrm{g}$ of pYE1170 was digested with EcoRI and then treated

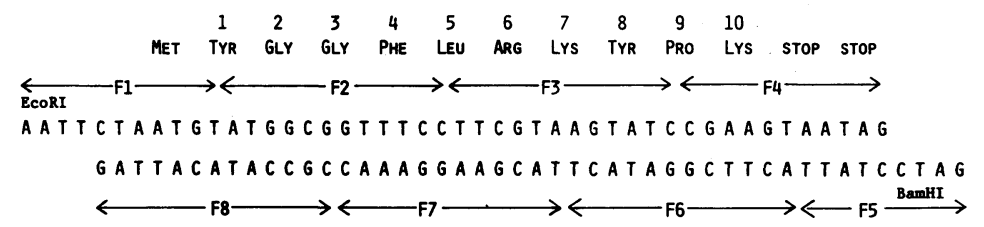

FIG. 1. Design of the Synthetic $\alpha$ NE Gene.

The $5^{\prime}$ ends of the gene have cohesive termini identical to the sequences generated by the Eco RI and Bam HI restriction endonucleases so that the gene is inserted correctly into plasmids. Eight oligodeoxyribonucleotide fragments, labeled F1 through F8, were synthesized and ligated to construct the gene as described under Materials AND Methods.
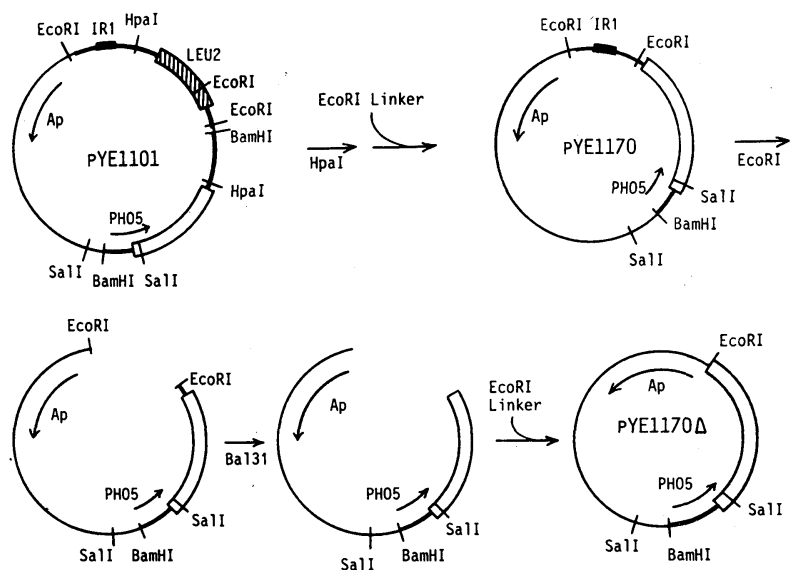

FIG. 2. Construction of pYE1170ג.

See Materials AND Methods for a detailed description. Plasmid DNA shown as thin and thick lines is of pBR322 and yeast origin, respectively. IR1 ( $\square$ ) is one of the inverted repeat sequences of the $2 \mu \mathrm{m}$ DNA of yeast. $\square$, APase structural gene; , LEU2 gene of yeast. Arrows indicate the transcription direction. 


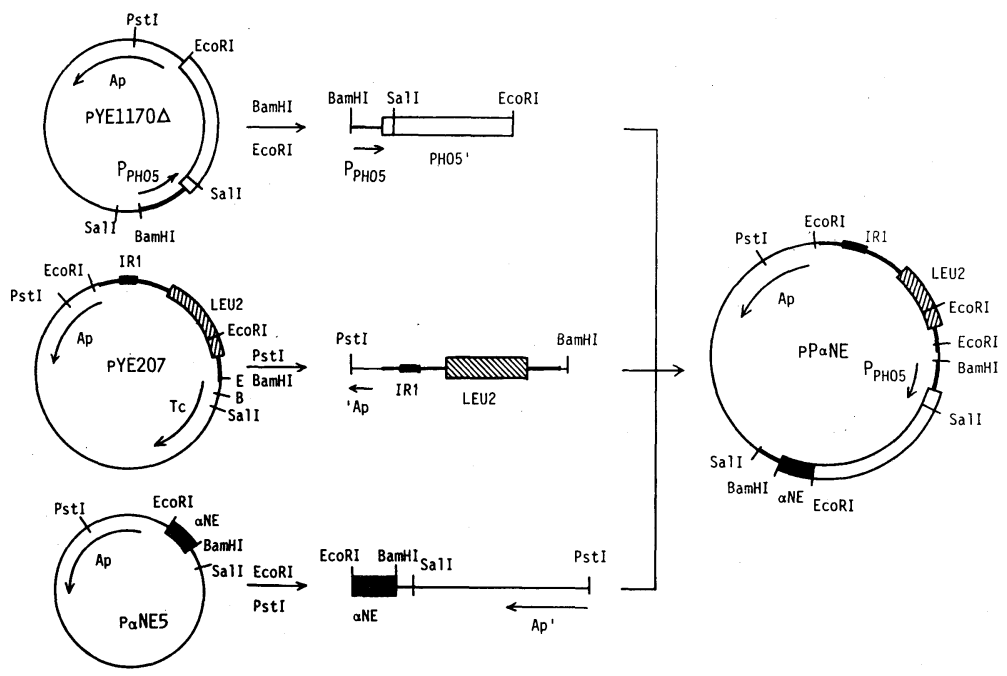

FIG. 3. Scheme for the Construction of the Expression Vector of the APase- $\alpha$ NE Chimeric Proteins.

The details were given under Materials AND Methods. $\square$, synthetic $\alpha$ NE gene. PH05' denotes the PHO5 gene whose coding region for the C-terminus of APase has been deleted. 'Ap and Ap' are parts of the ampicillin resistance gene produced on Pst 1 digestion. $P_{\mathrm{PH} 05}$ is the promotor of the PH05 gene. pYE1170A represents pYE1170 1, 2, 3 and 4. Other symbols are the same as those in Fig. 2.

with Bal 31 (0.5 units) in a buffer solution containing $20 \mathrm{~mm}$ Tris- $\mathrm{HCl}$ (pH 8.1), $100 \mathrm{~mm} \mathrm{NaCl}$ and $12 \mathrm{~mm} \mathrm{CaCl}_{2}$ at $30^{\circ} \mathrm{C}$ for 3 minutes. Approximately $200 \sim 400$ base pairs were removed from the DNA termini by this treatment. The DNA fragments and $1 \mu \mathrm{g}$ of phosphorylated EcoRI linker were mixed and ligated with T4 DNA ligase. The resulting DNA (pYE1170 $\Delta$ ) was used to transform E. coli, and four plasmids, designated as pYE1170 1, 2, 3 and 4, which were about $6.2-\mathrm{kb}$ long and has a single $\dot{E} c o$ RI cleavage site, were isolated from the ampicillin-resistant transformants.

Five $\mu$ g each of three plasmids, pYE1170 $1,2,3$ or 4 , pYE207 and p $\alpha$ NE5 were cleaved with the combination of endonucleases BamHI-EcoRI, PstI-BamHI and EcoRIPst I respectively, and then subjected to agarose gel electrophoresis. The three DNA fragments shown in Fig. 3 were isolated, mixed and then treated with T4 DNA ligase for 18 hours at $15^{\circ} \mathrm{C}$. The resultant plasmids were designated as $\mathrm{pP} \alpha \mathrm{NE} 41,42,43$ and 44, depending on the origin of the PHO5 gene, i.e. pYE1170A 1, 2, 3 and 4, respectively.

Radioimmunoassay for $\alpha N E$. As the synthetic $\alpha \mathrm{NE}$ gene was designed so as to have an additional methionine codon (ATG) at the $\mathrm{N}$-terminus of the mature form of $\alpha \mathrm{NE}$, free $\alpha \mathrm{NE}$ molecules can be obtained through $\mathrm{BrCN}$ cleavage of the chimeric protein.

A sample fraction was treated with $70 \%$ formic acid containing $\mathrm{BrCN}$ in the dark for 24 hours. Then the reaction mixture was lyophilized, and the $\alpha \mathrm{NE}$ was extracted with $0.1 \mathrm{ml}$ of $1.3 \mathrm{M}$ Tris- $\mathrm{HCl}(\mathrm{pH} 8.0)$ and sub- jected to radioimmunoassay (RIA) according to the method described by Minamino et al. ${ }^{8)}$

Others. Transformation of the yeast strain was carried out by the procedure of Beggs ${ }^{9)}$ except that Zymolyase60,000 was used instead of Helicase. The enzyme activity of the repressible acid phosphatase was assayed according to the method described by Toh-e et al. ${ }^{1)}$

\section{RESULTS}

\section{Expression of the cloned PHO5 gene in Sac-} charomyces cerevisiae

The PHO5 gene coding for the repressible acid phosphatase (APase) was obtained from the chromosomal DNA of Saccharomyces cerevisiae as a $c a$. 3.2-kb DNA fragment and cloned on a yeast- $E$. coli shuttle vector. ${ }^{4)}$ The plasmid carrying this $3.2-\mathrm{kb}$ DNA fragment, designated as pYE1101, was able to transform the PH05 yeast strain, XP3-7A, to the $\mathrm{Pho}^{+}$ phenotype. This plasmid was stably maintained in the yeast cells, and the transformants cultured in the phosphate-poor medium produced and secreted large amounts of the acid phosphatase (APase). ${ }^{4)}$

The production of the acid phosphatase with a low concentration of phosphate (low $\mathrm{Pi}$ ) 
Table I. Production of Acid Phosphatase in Yeast XP3-7A Carrying Plasmid pYe1101

\begin{tabular}{|c|c|c|c|c|}
\hline \multirow{2}{*}{ Medium $^{a}$} & \multirow{2}{*}{ Plasmid } & \multirow{2}{*}{$\frac{\text { Cell density }}{\mathrm{OD}_{660}}$} & \multicolumn{2}{|c|}{ Activity of APase } \\
\hline & & & $\mathrm{OD}_{420}($ per min $)$ & $\mathrm{OD}_{420} / \mathrm{OD}_{660}$ \\
\hline \multirow{2}{*}{$+\mathrm{Pi}$} & - & 16.5 & 0.005 & 0.0003 \\
\hline & pYE1101 & 14.2 & 0.450 & 0.032 \\
\hline \multirow{2}{*}{$-\mathrm{Pi}$} & - & 10.0 & 0.250 & 0.025 \\
\hline & pYE1101 & 6.25 & 2.800 & 0.448 \\
\hline
\end{tabular}

${ }^{a}+\mathrm{Pi}$ and $-\mathrm{Pi}$ indicate high and low phosphate medium, respectively. Cells were cultivated in $+\mathrm{Pi}$ or $-\mathrm{Pi}$ medium and then submitted to the enzyme assay. ${ }^{1}{ }^{\text {) }}$

Table II. Production of $\alpha$ NE in Yeast XP3-7A Carrying Various Plasmids

\begin{tabular}{|c|c|c|c|c|}
\hline \multirow{2}{*}{ Medium } & \multirow{2}{*}{ Plasmid } & \multirow{2}{*}{ No. of cells $/ \mathrm{ml}^{a}$} & \multicolumn{2}{|c|}{ Amount of $\alpha \mathrm{NE}^{b}$} \\
\hline & & & $\mathrm{ng} / \mathrm{ml}$ & molecules/cell \\
\hline \multirow{4}{*}{$+\mathrm{Pi}$} & pYE1101 & $5.2 \times 10^{7}$ & 0.01 & - \\
\hline & $\mathrm{pP} \alpha \mathrm{NE} 41$ & $5.0 \times 10^{7}$ & 0.8 & $8.0 \times 10^{3}$ \\
\hline & $\mathrm{pP} \alpha \mathrm{NE} 42$ & $4.9 \times 10^{7}$ & 0.5 & $5.1 \times 10^{3}$ \\
\hline & $\mathrm{pP} \alpha \mathrm{NE} 43$ & $4.8 \times 10^{7}$ & 0.5 & $5.2 \times 10^{3}$ \\
\hline \multirow{4}{*}{$-\mathrm{Pi}$} & pYE1101 & $3.0 \times 10^{7}$ & 0.18 & - \\
\hline & $\mathrm{pP} \alpha \mathrm{NE} 41$ & $2.0 \times 10^{7}$ & 46.3 & $1.2 \times 10^{6}$ \\
\hline & $\mathrm{pP} \alpha \mathrm{NE} 42$ & $2.2 \times 10^{7}$ & 50.0 & $1.1 \times 10^{6}$ \\
\hline & $\mathrm{pP} \alpha \mathrm{NE} 43$ & $1.9 \times 10^{7}$ & 70.0 & $1.8 \times 10^{6}$ \\
\hline
\end{tabular}

a The yeast cell number was determined with a haemacytometer.

$b$ RIA for $\alpha$ NE was performed as described under MATERIALS AND METHODS.

was compared with that with a high concentration (high Pi) (Table I). The production of APase per cell under the high Pi conditions was one-tenth of that under the low Pi conditions. This clearly indicates that the expression of the PHO5 gene located on the plasmid is repressed by inorganic phosphate in the same manner as that of the gene located on the chromosome, suggesting that the foreign gene cloned into the plasmid could be expressed by using the control system of the PHO5 gene. To confirm this possibility, the expression of a chemically synthesized $\alpha \mathrm{NE}$ gene fused to the structural region of the PHO5 gene was studied.

\section{Expression of the PH05- $\alpha$ NE chimeric gene}

A yeast strain XP3-7A was transformed with expression vectors which had been constructed as described under MATERIALS AND
Methods, and the transformants were cultivated in low and high Pi media. After the cells had been treated with ice-cold acetone and lyophilized, they were submitted to RIA as described under MAterials AND Methods. As shown in Table II, $\alpha$ NE was produced at the level of $10^{6}$ molecules per cell when cells transformed with $\mathrm{pP} \alpha \mathrm{NE} 41,42$ or 43 were grown under the low $\mathrm{Pi}$ conditions. The production of $\alpha \mathrm{NE}$ in the low Pi cultures was about 200 times as high as that under the high $\mathrm{Pi}$ conditions, indicating that the expression of the $\alpha \mathrm{NE}$ gene was controlled by the regulatory system of the PHO5 gene.

To determine how the $\alpha \mathrm{NE}$ gene was inserted into the PHO5 gene, $\mathrm{pP} \alpha \mathrm{NE} 41,42$ and 43 were digested with $\mathrm{BamHI}$, and the resulting smaller fragments containing the $\alpha \mathrm{NE}$ gene were subjected to nucleotide sequence analysis according to the Maxam-Gilbert method. ${ }^{10}$ ) 


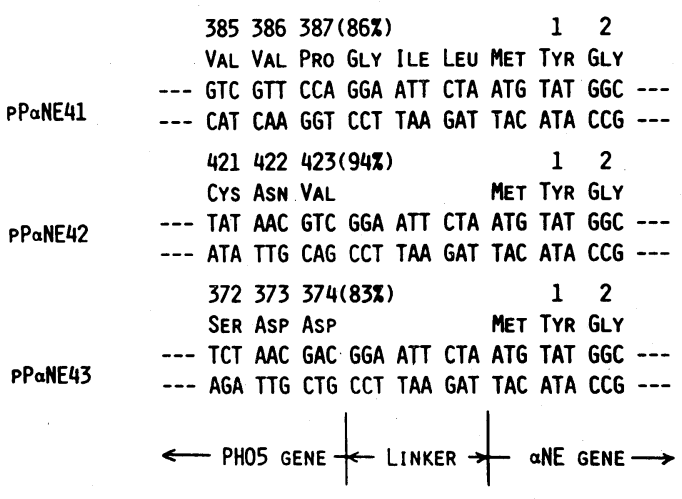

FIG. 4. The Nucleotide Sequences Surrounding the Junction between the PHO5 and Synthetic $\alpha$ NE Genes.

The nucleotide sequencing was carried out according to the method described by Maxam and Gilbert. ${ }^{10)}$ The amino acids predicted from the $\mathrm{PHO5}$ gene sequence ${ }^{4)}$ are numbered from the $\mathrm{N}$-terminus of the APase. The numbers in parentheses are the ratios of the number of amino acids in the APase portion to that in the APase- $\alpha \mathrm{NE}$ chimeric protein.

The results showed that the synthetic $\alpha \mathrm{NE}$ genes in $\mathrm{pP} \alpha \mathrm{NE} 41,42$ and 43 were connected through the EcoRI linker to the PHO5 gene at positions corresponding to the $387 \mathrm{th}$, 423rd and 374th amino acid residues from the $\mathrm{N}$ terminus of the mature APase, respectively (Fig. 4). Since the mature APase consists of 450 amino acids, this result indicates that the C-terminal portion comprising $6 \sim 17 \%$ of the intact enzyme was replaced by $\alpha$ NE. In each case, the $\alpha \mathrm{NE}$ gene was in phase with the reading frame of the $\mathrm{PHO5}$ gene. Thus, it was concluded that $\alpha \mathrm{NE}$ was produced as a chimeric protein with the APase and was released through cleavage at the methionine residue from the chimeric protein on cyanogen bromide treatment.

No $\alpha$ NE production was detected on RIA in the transformants carrying $\mathrm{pP} \alpha \mathrm{NE} 44$ (data not shown). The $\alpha \mathrm{NE}$ gene in this plasmid might be connected to the PHO5 gene out of phase of the reading frame, although nucleotide sequence analysis was not carried out to confirm this.

\section{Location of the APase- $\alpha$ NE chimeric proteins}

It is well established that the repressible
TABle III. Location of APase- $\alpha$ NE Chimeric Proteins in Yeast Cells

\begin{tabular}{|c|c|c|c|}
\hline \multirow{2}{*}{ Plasmid } & \multicolumn{3}{|c|}{$\begin{array}{l}\text { Relative amount of } \alpha \mathrm{NE} \text { or } \mathrm{APase}^{a} \\
\text { in cellular fractions }\end{array}$} \\
\hline & Whole cell & Protoplast & Periplasm \\
\hline $\mathrm{pP} \alpha \mathrm{NE} 41$ & $100 \%$ & $63 \%$ & $1.2 \%$ \\
\hline $\mathrm{pP} \alpha \mathrm{NE} 42$ & $100 \%$ & $55 \%$ & $1.3 \%$ \\
\hline $\mathrm{pP} \alpha \mathrm{NE} 43$ & $100 \%$ & $61 \%$ & $1.1 \%$ \\
\hline pYE1101 & $(100 \%)$ & $\mathrm{ND}^{b}$ & $(85.0 \%)$ \\
\hline
\end{tabular}

a The amount of $\alpha$ NE was measured by RIA. APase activity was measured as in Table I and is indicated in parentheses. The results are normalized with respect to the activity in the whole cell fraction.

$b \quad$ Not determined.

APase encoded by the PHO5 gene is glycosylated during secretion across the membrane and is located in the periplasmic space. ${ }^{11)}$ This raises the possibility that the APase- $\alpha$ NE chimeric proteins are located in the periplasmic space of the $\alpha \mathrm{NE}$ producing transformants.

To investigate this possibility, protoplasts were prepared from the yeast transformants as follows. After transformants had been cultivated overnight at $30^{\circ} \mathrm{C}$ in $4 \mathrm{ml}$ of the low $\mathrm{Pi}$ medium, a one $\mathrm{ml}$ aliquot of each culture was centrifuged and used for the preparation of protoplasts. Approximately $2 \sim 5 \times 10^{7}$ cells were incubated for one hour at $30^{\circ} \mathrm{C}$ in $2 \mathrm{ml}$ of reaction mixture containing $1.2 \mathrm{M}$ sorbitol, 50 mM citrate buffer ( $\mathrm{pH} 6.0$ ), $25 \mathrm{~mm}$ DTT and $0.1 \mathrm{~g} / \mathrm{ml}$ Zymolyase-60,000. Protoplasts collected by centrifugation were washed with $1.2 \mathrm{~m}$ sorbitol and then stocked as the protoplast fraction. The supernatant fraction after removal of the protoplasts was dialyzed against water overnight at $4{ }^{\circ} \mathrm{C}$ and then lyophilized. This fraction was stocked as the periplasmic fraction. The whole cell and culture medium fractions were obtained from another aliquot of the culture after centrifugation. The culture medium fraction was dialyzed against water at $4^{\circ} \mathrm{C}$ and lyophilized. Each fraction was submitted to the radioimmunoassay for $\alpha \mathrm{NE}$.

The results are summarized in Table III. 
Eighty-five per cent of the APase activity of the whole cell fraction was detected in the periplasmic fraction when cells carrying the intact PH05 gene cloned in pYE1101 were cultivated. This indicated that most of the mature APase, whose gene is located on the plasmid, was secreted and accumulated in the periplasmic space. APase activity equivalent to $10 \%$ of that of the whole cells was detected in the culture medium (data not shown).

If the APase- $\alpha$ NE hybrid proteins are secreted in the same manner as the APase, one would expect to find $\alpha \mathrm{NE}$ mainly in the periplasmic and culture medium fractions prepared from cultures of yeasts transformed with $\mathrm{pP} \alpha \mathrm{NE} 41,42$ and 43 . However, $\alpha \mathrm{NE}$ activity was mainly detected in the protoplast fraction and only a basal level was detected in the periplasmic fraction (Table III) as well as in the culture medium (data not shown). These results strongly suggested that the hybrid proteins were not secreted out through the cell membrane and accumulated in the cytoplasm or at the cytoplasmic membrane even though they contained almost the entire APase portion in their sequences.

\section{DISCUSSION}

Gene engineering technology has made it possible to produce foreign cell peptides in microorganisms. ${ }^{12)}$ In the study presented here, plasmids which carried the synthetic $\alpha \mathrm{NE}$ gene fused to the PHO5 gene coding for the repressible acid phosphatase (APase) of $S$. cerevisiae were constructed and used for the production of $\alpha \mathrm{NE}$ in yeast cells. The production of $\alpha \mathrm{NE}$ was detected in three of the four transformants carrying the fused genes. The production levels of $\alpha \mathrm{NE}$ in the transformants reached $10^{6}$ molecules per cell under the derepressed conditions and the productivity was approximately 200 times as much as that under the high $\mathrm{Pi}$ conditions (Table II). Compared to the high induction ratio of APase- $\alpha \mathrm{NE}$ chimeric proteins, the induction ratio of the APase in the transformant carrying the PHO5 gene on pYE1101 was only 14 (Table I). This can be explained by the fact that the transformant expressed about 100 times more APase than the parent yeast, XP3-7A, under the high $\mathrm{Pi}$ conditions. This level of expression was comparable to that in derepressed XP3-7A (Table I). Apparently, the presence of a high dosage of the PHO5 gene including the regulatory region carried by multiple copies of the plasmids affected the control of some of the chromosomal APase genes such as those for constitutive APase $(P H 03)^{1)}$ and/or another repressible APase $(P H O X) .{ }^{13)}$ The true mechanisms underlying this phenomenom are not clear at present and require further investigation.

In spite of this phenomenom, the results strongly suggest that the PHO5 gene system, whose expression is controlled by the concentration of $\mathrm{Pi}$ in the culture medium, is a very useful tool for the production of foreign peptides in the yeast.

The mechanisms of secretion of peripheral proteins from the cytoplasm have been investigated from the viewpoints of protein chemistry and molecular genetics. ${ }^{14)}$ Inouye and Halegoua postulated the essential role of the signal sequence in the secretion of proteins in the $E$. coli system. ${ }^{15)}$ It has also been reported that several mutations in the signal sequence of the maltose binding protein prevent the export of the protein, resulting in the accumulation of its precursor form in the cytoplasm. ${ }^{16)}$ On the other hand, it was found that a hybrid molecule of the maltose binding protein and $\beta$-galactosidase was not translocated across the inner membrane, even when the hybrid protein contained almost the entire maltose binding protein structure including its signal segment. ${ }^{17)}$ It was also demoristrated that a chimeric protein of $E$. coli alkaline phosphatase and $\alpha \mathrm{NE}$ was not transported into the periplasmic space of $E$. coli in a significant amount even though only approximately 30 out of the 449 amino acid residues of the alkaline phosphatase were replaced by $\alpha \mathrm{NE}$ consisting of 10 amino acid residues. ${ }^{18)}$ These results suggest that translocation of 
proteins across the membrane depends not only on the signal peptides but also on the structures of the proteins following the signal sequences. ${ }^{17)}$

As shown in Table III, similar results were obtained when the C-terminal portion of the APase of the yeast, comprising about 6 to $17 \%$ of the intact enzyme, was replaced by $\alpha \mathrm{NE}$. In this case, only basal levels of $\alpha \mathrm{NE}$ activity were detected in the periplasmic and culture medium fractions. The possibility that $\alpha \mathrm{NE}$ in the periplasmic fraction is degraded during the protoplast preparation cannot be completely ruled out because we recovered $55 \sim 65 \%$ of the total cell $\alpha \mathrm{NE}$ in the protoplast (cytoplasmic) fraction. Another possibility that the hybrid proteins are degraded rapidly after their secretion into the periplasmic space is also left for further study.

If the hybrid proteins are really not secreted as in the case of the E. coli system, the possible mechanisms underlying the phenomenon will be as follows. ${ }^{18)}$ The conformation of a protein itself plays some role in preventing its transportation into the periplasmic space and unfavorable conformations are assumed by the chimeric proteins in this case. The second possibility is that $\alpha \mathrm{NE}$ at the $\mathrm{C}$-termini of the hybrid proteins are somehow trapped by the cytoplasmic membrane which prevents the secretion of the proteins. In this context, it should be noted that the $\alpha \mathrm{NE}$ sequence is not particularly hydrophobic, which will facilitate the trapping.

Studies using other foreign genes and secretion systems to clarify these points are now in progress.

\section{REFERENCES}

1) A. Toh-e, Y. Ueda, S. Kakimoto and Y. Oshima, $J$. Bacteriol., 113, 727 (1973).

2) A. Toh-e, S. Inouye and Y. Oshima, J. Bacteriol., 145, 221 (1981).

3) G. Schmidt, G. Bartsch, M. Laumont, T. Herman and M. Liss, Biochemistry, 2, 126 (1963).

4) K. Arima, T. Oshima, I. Kubota, N. Nakamura, T. Mizunaga and A. Toh-e, Nucl. Acids Res., 11, 1657 (1983).

5) S. Tanaka, T. Oshima, K. Ohsue, T. Ono, S. Oikawa, I. Takano, T. Noguchi, K. Kangawa, N. Minamino and H. Matsuo, Nucl. Acids Res., 10, 1741 (1982).

6) K. Kangawa, N. Minamino, N. Chino, S. Sakakibara and H. Matsuo, Biochem. Biophys. Res. Commun., 99, 871 (1981).

7) A. Miyanohara, A. Toh-e, C. Nozaki, F. Hamada, N. Ohtomo and K. Matsubara, Proc. Natl. Acad. Sci. U.S.A., 80, 1 (1983).

8) N. Minamino, K. Kitamura, Y. Hayashi, K. Kangawa and H. Matsuo, Biochem. Biophys. Res. Commun., 102, 226 (1975).

9) J. D. Beggs, Nature, 275, 104 (1978).

10) A. M. Maxam and W. Gilbert, "Methods in Enzymology," Vol. 65, ed. by L. Grossman and K. Moldave, Academic Press Inc., New York, 1980, p. 499.

11) P. Bore and E. P. Steyn-Parvé, Biochim. Biophys. Acta, 128, 400 (1966).

12) K. Itakura, T. Hirose, R. Crea, A. D. Riggs, H. L. Heyneker, F. Bolivar and H. W. Boyer, Science, 198, 1056 (1977).

13) R. A. Kramer and N. Andersen, Proc. Natl. Acad. Sci. U.S.A., 77, 6541 (1980).

14) B. D. Davis and P. C. Tai, Nature, 283, 433 (1980).

15) M. Inouye and S. Halegoua, CRC Crit. Rev. Biochem., 7, 339 (1980).

16) H. Bedouelle, P. J. Bassford, Jr., A. V. Fowler, I. Zabin, J. Beckwith and M. Hofnung, Nature, 285, 78 (1980).

17) P. J. Bassford, Jr., T. J. Silhavy and J. R. Beckwith, J. Bacteriol., 139, 19 (1979).

18) K. Ohsuye, M. Nomura, S. Tanaka, I. Kubota, H. Nakazato, H. Shinagawa, A. Nakata and T. Noguchi, Nucl. Acids Res., 11, 1283 (1983). 